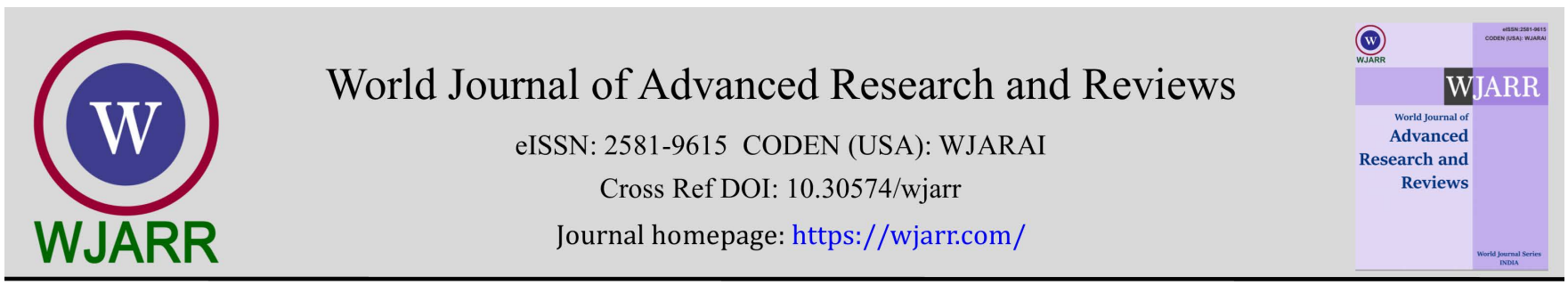

(REVIEW ARTICLE)

Check for updates

\title{
Design and development of a hybrid flat-bed relief printmaking machine - A review
}

\author{
Wale Oloidi ${ }^{1,}{ }^{*}$, Igwe 0 Ewona ${ }^{2}$ and David 0 Fakorede ${ }^{3}$ \\ ${ }^{1}$ Department of Visual Arts, Cross River University of Technology, Calabar, Nigeria. \\ 2 Department of Physics, Cross River University of Technology, Calabar, Nigeria. \\ ${ }^{3}$ Department of Mechanical Engineering, Cross River University of Technology, Calabar, Nigeria.
}

World Journal of Advanced Research and Reviews, 2022, 13(01), 552-555

Publication history: Received on 17 December 2021; revised on 19 January 2022; accepted on 21 January 2022

Article DOI: https://doi.org/10.30574/wjarr.2022.13.1.0068

\begin{abstract}
Printmaking is an area of visual arts which deals with different processes in the multi-production of art works. The study discusses the various methodologies and processes involved in printmaking such as the linocut technique, etching, line engraving, aquatint and deep etching techniques otherwise known as intaglio. Of particular interest is the intaglio technique of printmaking, from design conceptualization to details of printing processes. Teaching and training in this field has metamorphosed into a fast digital lane. This has been difficult for the developing parts of the world to catch up. A hybrid flat-bed relief printmaking machine is proposed in this work. The machine employs both manual and electric motor technology for running the rolling parts. In this way a smooth transition is envisage from the conventional manual machine to the digital machines that are used in the industrialization of the textile industry.
\end{abstract}

Keywords: Hybrid; Printmaking machine; Auto printmaking; Manual printmaking

\section{Introduction}

When it comes to printmaking, there are various options to use depending on what you want to print and more importantly, what type of material you want to print onto. Depending on the printmaking technique you choose, you'll need a specific type of printmaking press, which is what we'll be looking at in this article. But first, let's take a closer look at the printmaking press itself.

A general overview of printmaking can be found in [1]. The study discusses various materials that are used in printmaking, their types and material potentials. This is followed by a critical discussion of various printmaking processes such as the linocut technique, etching, line engraving, aquatint and deep etching techniques otherwise known as intaglio. More specific studies focus on the intaglio printmaker. Here, we are presented with a picture of a printmaker who specializes in the intaglio technique. Data available here is quite invaluable to anyone who may be interested in the intaglio technique of printmaking, from design conceptualization to details of printing processes in exploring the intaglio technique. The author in [2], on the other hand, provides some useful insights into the fabrication of a slab maker although this impacts the present study, it does so only tangentially as a parallel data source

Printmaking involves the application of different types of colouring agents unto a specific surface, under pressure, in order to create a text or an image. Directly imported printmaking machines are very expensive in the context of Nigeria's fragile economy. There is now an urgency for a production shift from a manual to a manual/electric printmaking machine.

\footnotetext{
* Corresponding author: Wale Oloidi

Department of Visual Arts, Cross River University of Technology, Calabar, Nigeria.

Copyright (C) 2022 Author(s) retain the copyright of this article. This article is published under the terms of the Creative Commons Attribution Liscense 4.0.
} 
Printmaking is an area of visual arts which deals with different processes in the multi-production of art works. It involves the application of different types of colouring agents unto a specific surface, under pressure, in order to create a text or an image. Most manual printmaking machines suffer from worn out parts and poor maintenance because most of them were important. More compounding is the fact that this analog machine no longer fits into the functional requirements of a digital age. Directly imported printmaking machines are very expensive in the context of Nigeria's fragile economy. There is an urgency for a production shift from a manual to a manual/electric printmaking machine. This can be met with a planned fabrication of a hybrid Flat-Bed Relief Printmaking Machine which will have the capacity for a multi-production of prints because of its technical efficiency. It can both function manually and electrically, thus overcoming the severe constraints of the non-functioning manual printmaking machine in the department

The author in [2], on the other hand, provides some useful insights into the fabrication of a slab maker although this impacts the present study, it does so only tangentially as a parallel data source.

\section{Manual Printmaking}

Manual printmaking machine suffers from the afflictions of age and lack of maintenance. Manual machines or analog machines do not fit into the functional requirements of a digital age thus the need for digitalizing printmaking. There are often found in teaching departments of universities especially in developing parts of the world. This creates a huge gap between educational institutions and the industry. This is one reason why graduates from such institutions are said to be unemployable. Electric or digital printmaking are not only alien to the but expensive for most educational institutions. This is the reason that replacing them has been difficult especially that most institutions in the development world are underfunded.

\section{Auto Printmaking}

Developed economies should look inward in developing home grown technology if it hopes to be from overdependence on importation and capital flight. This can be met with a planned fabrication of a hybrid flat-bed relief printmaking machine which will have the capacity for a multi-production of prints because of its technical efficiency. It can both function manually and electrically, thus overcoming the severe constraints of the non-functioning manual printmaking machine in the one hand and providing a smooth transition to the digital age on the other hand. Such replacement may involve the design and local fabrication of the hybrid machine to safe the cost of importation of more advanced machines.

For a functional hybrid flat-bed Relief printmaking machine, the following objectives of the production plan should include the development of a functional design and the right specifications, followed by an adapted technological process that makes it possible to fabricate this machine. The significance of the study derives from the fact that the fabrication of such a relief printmaking machine will facilitate the teaching of students in the area of printmaking techniques because of the advantages of the capacity of the printmaking machine in functioning both manually and electrically. In this way, the use of the relief printmaking machine will ensure continuity in the offering of art pedagogy to the students from year to year without any embarrassing interruptions posed by a worn-out relief print making machine.

In this way, the use of auto relief printmaking machine will ensure continuity in the offering of art pedagogy to the students from year to year without any embarrassing interruptions posed by a worn-out relief print making machine. The proposed fabrication is an act of technical necessity as it will help to overcome the challenge posed by old and wornout manual printmaking machines in the teaching of graphic designs our institutions of learning.

Such effort is also expected to operationalize printmaking and the proposed printmaking machine project will become effective in the multiple production of a prototype design/image. It will also enhance teaching and the ability of the lecturers to offer useful pedagogy on printmaking using the printmaking machine as a model for its functional capacity and efficiency.

\section{Types of printmaking}

The printing press was invented by Johannes Gutenberg in 1440. Today, there are numerous types of printmaking press, each suited to different techniques. Each printmaking technique, and thus each type of printmaking press, is suited to different artistic values, specific products or services. It was a mechanical device used to apply the necessary pressure 
to an inked surface placed on a fabric or paper, which allows for ink transfer. However, for the purpose of teaching, it is important to have a general-purpose machine.

\subsection{Flatbed Press}

Flatbed press (as contrasted with rotary press which has a cylindrical printing surface) is a printing press which employs a flat surface against which paper is pressed, either by another flat surface acting reciprocally or by a cylinder rolling over it [3].

\subsection{Adana Letter Press}

The Adana letter press is a letterpress as well as small relief and block prints. There were originally made for hobby printers, but have grown for commercial fashion.

\subsection{Lithography Press}

While intaglio presses can be used for many different techniques, a lithography press is used exclusively for surface printing from a smooth lithographic limestone or metal plate. Most books and magazines today are printed using offset lithography. Due to the weight of the stone itself, most lithography presses are bulky and costly which makes them unsuitable for small studio spaces.

\subsection{Relief / Lino Printing Press}

The Albion Press is a great example of an early relief printing press. This model is an iron hand printing press, originally from the 1820's. It worked via a simple toggle action. While they can be great for relief printing techniques such as lino and block printing. They are extremely expensive due to their vintage nature and size [4].

\subsection{Intaglio / Etching Press}

Intaglio presses are used for techniques like etching, aquatint, mezzotint, engraving and dry point. They are rather simple, encompassing two heavy rollers with a flat, hard bed suspended in between. In order to operate the press, the user must operate one of the rollers, applying pressure to the matrix and thus transferring the design onto a dampened sheet of paper. Usually, a piece of felt or a thin blanket is used to ensure that the pressure is spread evenly and the paper "picks up" all of the ink from the matrix. Set to a lower pressure output, intaglio presses can also be used for lino and relief printing.

\section{Methodology for the hybridization of flat-bed relief printmaking machine}

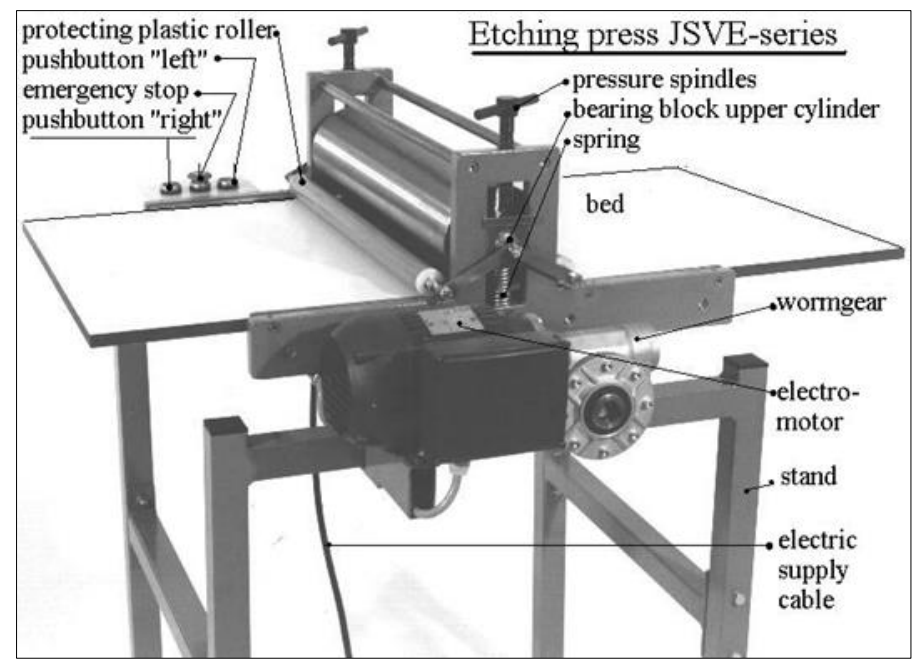

Figure 1 A typical design of a hybrid printmaking machine adapted from [5]

Methodology follows a production action plans. In terms of description, the study has to do with the study of a hybrid flat-bed relief printmaking machine as a replacement for a dilapidated manual printmaking machine replete in most institutions of learning. To achieve the local production, it is suggested there should first and foremost be the need to source for data, both primary and secondary. Conduct data analysis which will provide the basis for the 
conceptualization of studied designs. Then comes the sourcing of local materials, their processing and assemblage for the fabrication of a hybrid printmaking machine that operate both manually and electrically.

Materials to be sourced may include 18 Guage metal blade, 2" angle iron, upper and lower roller, gear and electric motor. Other necessary materials are steering, regulator, nut ' $n$ ' bolt, bearings and blankets. Production tools may include hammer, plier, hacksaw, measuring tape, sewing machine, cutting disk, filing stone, welding machine, vise, cranking machine, spanner and screw drivers. With these available, the production of a hybrid flat-bed relief printmaking machine can be assembled.

The hybrid printmaking machine should be subjected to descriptive and functional analysis of its operations and a possible evaluation of its functional capacity and efficiency. Figure 1 shows a typical design for a hybrid printmaking machine.

\section{Conclusion}

The dearth of teaching and learning materials in institutions of learning require innovative approaches to enhance the process. Quite often, the machines deployed for the purpose are old fashioned, with attendant breakdown, lack of experts and machine parts to fix them. Besides, the cost of importation of modern technology is rather expensive. Such is the case with printmaking machines for the teaching of graphics in tertiary institutions. Local fabrication of prototype machines become imperative.

There are, however, production problems implicated in a local production shift, namely: the sourcing of machine parts that can be reprocessed and retooled and reshaped to functional specifications. There is the other problem of evolving a homespun technology that can drive the printing machine at a level of efficiency and endow it with the capacity of producing multiple prints as may be desired. In this way, creative production in the area of printmaking is thus assured. The production of prototype machines that will increase local content in terms of materials and expertise is advocated.

The design of a hybrid flatbed printmaking machine is considered an all-purpose approach and a cost-effective way of producing a printmaking machine by incorporating electrical parts. It is not only simple in design but will make the teaching of printmaking both interesting and attractive.

\section{Compliance with ethical standards}

\section{Acknowledgments}

The authors wish to acknowledge the Tertiary Education Trust Fund, TETFund for sponsoring this project through the Institution Based Research, IBR intervention.

\section{Disclosure of conflict of interest}

There is no conflict of interest in this work.

\section{References}

[1] Beth G, Bill F. Printmaking: A Complete Guide to Materials and Processes. Prentice Hall. 2009.

[2] Edu P. Construction of Kick Wheel. Unpublished First-Degree Project, Department of Visual Arts and Technology, Cross River University of Technology, Calabar, Nigeria. 2011.

[3] Flatbed press. Flatbed press downloaded from https://www.britannica.com/technology/flatbed-press. 2022.

[4] Hyde J. Different types of printmaking press. Hickman Design. 2022.

[5] Polymetaal. Printmaking equipment. Etching press JSVE - Series. 2022. 